\title{
Improvement of sweet sorghum bagasse hydrolysis by alkali and acidic pretreatments
}

\author{
Amir Goshadrou ${ }^{1, *}$, Keikhosro Karimi ${ }^{1,2}$, Mohammad J. Taherzadeh ${ }^{2}$ \\ ${ }^{1}$ Department of Chemical Engineering, Isfahan University of Technology, Isfahan, 84156-83111, Iran \\ ${ }^{2}$ School of Engineering, University of Borås, SE-501 90 Borås, Sweden \\ * Corresponding author. Tel: +98 3113915623, Fax: +98 3113912677,E-mail:goshadrou@ce.iut.ac.ir
}

\begin{abstract}
The present work deals with enzymatic hydrolysis of sweet sorghum bagasse to fermentable sugars. The bagasse was treated with phosphoric acid and sodium hydroxide prior to enzymatic hydrolysis by commercial cellulase and $\beta$-glucosidase. The phosphoric acid pretreatment was performed at $50^{\circ} \mathrm{C}$ for $30 \mathrm{~min}$, while $12 \% \mathrm{NaOH}$ was used for the alkali treatment at $0^{\circ} \mathrm{C}$ for $3 \mathrm{~h}$. The phosphoric acid pretreatment resulted in improving the subsequent enzymatic hydrolysis up to $79 \%$ of the theoretical yield. However, the best results of enzymatic hydrolysis were obtained in the hydrolysis of pretreated bagasse by $\mathrm{NaOH}$ solution, where more than $92 \%$ of the theoretical sugar yield was obtained.
\end{abstract}

Keywords: Lignocellulosic material, Sweet sorghum, Enzymatic hydrolysis, Pretreatment

\section{Introduction}

Fossil fuel limitations and constraints on carbon dioxide emissions have a high impact in the market of bioethanol, which is the most commonly used biofuel for petrol substitution in the world [1]. Fermentative ethanol can be produced from a variety of feed stocks such as saccharine materials, starchy materials and many types of lignocellulosic waste and harvestings, whichever has the best well-to-wheel assessment [2]. Lignocellulosic biomass is considered a future alternative for the agricultural products that are currently used as raw material for bioethanol production, because it is more abundant and less expensive than food crops, especially when waste streams are used. Furthermore, the use of lignocellulosic biomass is more attractive in terms of energy balances and emissions [3]. Sweet sorghum is an interesting annual plant that can be cultivated in widespread areas from tropical to temperate climates with the potential to produce more ethanol per acre than corn [4]. In addition, it has a high yield of green biomass and different part of this plant, such as bagasse, can be hydrolyzed to fermentable sugar before further bioconversion to ethanol. Similar to all lignocellulosic biomass, the main components of SSB are cellulose, hemicellulose and lignin $[4,5]$. Hydrolysis of cellulose part can be carried out by dilute acid, concentrated acid or enzymatically, whereas the latter can be performed under mild condition with higher yield of glucose $[6,7]$. However, the main purpose of this article was to enzymatic hydrolysis of the sweet sorghum bagasse (SSB) to fermentable sugars. In any case, access of cellulase to cellulose and lignin strongly limits the efficiency of enzymatic hydrolysis because Lignin, which is a complex polymer, provides structural integrity in plants. Therefore, the pretreatment is an important process before hydrolysis in order to remove or alter lignin and increase the accessibility of enzyme to cellulose [3]. Among all methods available for the pretreatment of lignocelluloses, acidic and alkaline treatments have been proven to have practical advantages. Concentrated phosphoric acid can dissolve cellulose in the presence of water without inhibitory effect, while it is non-corrosive, safe to be used and inexpensive chemical [8]. Similarly, sodium hydroxide can remove the lignin barrier and reduce cellulose crystallinity and therefore, increase the accessibility of enzyme cellulose part [9]. In addition, both processes 
utilize lower temperatures and pressures compared to other pretreatment technologies and even may be carried out at ambient conditions.

The current study deals with the effect of sodium hydroxide (12\%) and phosphoric acid (85\%) pretreatments on improvement of sugar yield in enzymatic hydrolysis of sweet sorghum bagasse.

\section{Materials and Methods}

\subsection{Raw materials}

The sweet sorghum bagasse (Sofra, Italy) used in all experiments was kindly provided by Dr. A. Almodares (Department of Biology, University of Isfahan, Iran). The bagasse was initially dried at room temperature and then was hammer milled and screened to achieve a particle size in the range of 20-80 mesh.

\subsection{Sodium hydroxide pretreatment}

The sweet sorghum bagasse was treated with $12 \%$ (W/V) $\mathrm{NaOH}$ solution. A $5 \%$ bagasse suspension (based on the dry weight) was thoroughly mixed for $10 \mathrm{~min}$ at $0^{\circ} \mathrm{C}$, then placed in a laboratory ice-water bath for $3 \mathrm{~h}$ and mixed every $15 \mathrm{~min}$. The pretreated materials were then washed with distilled water until $\mathrm{pH} 7$ was detected. The solids were then dried at $40 \pm 1^{\circ} \mathrm{C}$ until constant weight and kept in a refrigerator until use.

\subsection{Phosphoric acid pretreatment}

The bagasse was thoroughly mixed with phosphoric acid $(85 \%)$ in a $50 \mathrm{~mL}$ plastic centrifuge tube at $12.5 \%$ solid loading. The mixture shacked at $90 \mathrm{rpm}$ and the temperature was controlled at $50 \pm 1^{\circ} \mathrm{C}$ for $30 \mathrm{~m}$ in. The treated slurry was then washed with $20 \mathrm{~mL}$ cold acetone and centrifuged at $4000 \mathrm{rpm}$ for $20 \mathrm{~min}$. The washing process was repeated three times with $40 \mathrm{~mL}$ acetone, followed by three times with $40 \mathrm{~mL}$ distilled water. The residual acetone from washing stages was removed from supernatant after simple evaporation in a fume hood. The treated bagasse was finally washed by hot distilled water to neutralize the $\mathrm{pH}$ to 7 .

\subsection{Enzymatic hydrolysis}

Commercial cellulase (Celluclast 1.5L, Novozyme, Denmark) and $\beta$-glucosidase (Novozyme 188, Novozyme, Denmark) were used for all enzymatic hydrolysis. Celluclast 1.5-L showed 87 FPU/ml activity, measured according to the procedure presented by Adney and Baker [10], while $\beta$-glucosidase activity was $240 \mathrm{IU} / \mathrm{ml}$ according to Ximenes et al. method [11]. The hydrolysis process was performed at $45 \pm 0.5^{\circ} \mathrm{C}$ in $50 \mathrm{~mL}$ sodium citrate buffer $(0.05 \mathrm{M})$ using $115 \mathrm{~mL}$ glass bottles. The initial $\mathrm{pH}$ was adjusted to $4.8 \pm 0.1$, and substrate concentration was $20 \mathrm{~g} / \mathrm{L}$ dry weight for untreated and pretreated materials. The suspension was then autoclaved at $121^{\circ} \mathrm{C}$ and preincubated for 20 min prior to addition of enzymes. The enzymes loadings for hydrolysis were 20 FPU cellulase and $50 \mathrm{IU} \beta$-glucosidase per grams of dry substrates. The reaction mixture hydrolysis performed at $120 \mathrm{r}$ pm for $72 \mathrm{~h}$ a nd the samples were periodically taken for sugar analysis. The yield of enzymatic hydrolysis was calculated as a ratio of theoretical glucose production yield using the following equation:

Yield of enzymatic hydrolysis $(\%)=\frac{\text { Produced glucose }(g / L) \times 100}{1.111 \times \text { Substrate concentration }(g / L) \times F}$ 
where $\mathrm{F}$ in denominator is the biomass glucan fraction, which is presented in Table 1 for untreated and different pretreated bagasse. The conversion factor of 1.111 was applied to consider the conversion of glucan to glucose.

\subsection{Analytical methods}

The untreated and pretreated sweet sorghum bagasse were analyzed for carbohydrate and lignin (acid-soluble and insoluble) according to the method presented by Sluiter et al. [12]. The method was based on de gradation of carbohydrates to monomeric sugars by two-stage acid hydrolysis and quantification of the sugars by HPLC. Furthermore, the acid-soluble was determined by $\mathrm{UV} /$ vis spectroscopy at $320 \mathrm{~nm}$, and acid-insoluble lignin contents was determined by drying of the acid treated samples at $575^{\circ} \mathrm{C}$.

The structural properties of the bagasse, before and after pretreatment by sodium hydroxide were analyzed by Fourier transform infrared (FTIR) spectrometer (Impact 410, Nicolet Instrument Corp., Madison, WI). The spectra were obtained using 60 scans of the samples with resolution of $4 \mathrm{~cm}-1$ in the range of 600 to $4,000 \mathrm{~cm}-1$. Nicolet OMNIC 4.1 analyzing software was used for correcting baseline and smoothing of the spectra.

Scanning electron microscopy (SEM) was used for study of the effect of pretreatments on physical property changes in the biomass. The freeze-dried samples were placed on carbon taps and subjected to the high performance scanning electron microscope (Quanta 200 ESEM FEG, FEI, ORA) and the micrographs were taken using an Everhart Thornley Scanning Electron Detector (ETD) at $20 \mathrm{Kv}$ and a high vacuum mode.

The detection of sugars including glucose, xylose, mannose, galactose, and arabinose in the hydrolyzates and carbohydrate analyses were performed by High performance liquid chromatography using an anion-exchange column (Aminex HPX-87P, Bio-Rad) at $85^{\circ} \mathrm{C}$ with 0.6 $\mathrm{ml} / \mathrm{min}$ eluent of ultra-pure water.

All the experiments were performed in duplicates and all data reported in this paper are the average of the two replications.

\section{Results}

\subsection{Pretreatment and materials characterization}

The sweet sorghum bagasse used in this study mainly contained glucan (41.3\%), xylan (17.9\%), and lignin $(18.2 \%)$ (Table 1). The native bagasse was pretreated with $\mathrm{NaOH}$ solution at $0^{\circ} \mathrm{C}$ for 3 $\mathrm{h}$ and concentrated phosphoric acid for $30 \mathrm{~min}$ at $50^{\circ} \mathrm{C}$. The composition of the bagasse after the pretreatments was analyzed and results are presented in Table 1.

Table 1. Composition of the bagasse before and after pretreatments.

\begin{tabular}{llllllll}
\hline $\begin{array}{l}\text { Pretreatment } \\
\text { method }\end{array}$ & $\begin{array}{l}\text { Glucan } \\
(\%)\end{array}$ & $\begin{array}{l}\text { Xylan } \\
(\%)\end{array}$ & $\begin{array}{l}\text { Mannan } \\
(\%)\end{array}$ & $\begin{array}{l}\text { Galactan } \\
(\%)\end{array}$ & $\begin{array}{l}\text { Arabinan } \\
(\%)\end{array}$ & $\begin{array}{l}\text { Acid } \\
\text { soluble } \\
\text { lignin (\%) }\end{array}$ & $\begin{array}{l}\text { Acid } \\
\text { insoluble } \\
\text { lignin (\%) }\end{array}$ \\
\hline Untreated & 41.33 & 17.96 & 0.85 & 1.26 & 1.94 & 1.78 & 16.47 \\
Sodium hydroxide & 58.66 & 12.72 & 0.69 & 0.66 & 1.10 & 1.01 & 11.50 \\
Phosphoric acid & 52.25 & 11.88 & 0.34 & 0.39 & 0.46 & 1.15 & 23.02 \\
\hline
\end{tabular}


Glucan was the dominant component in all materials in the range of $41.3 \%$ to $58.6 \%$ and xylan was in the second place in the range of $11.8-17.9 \%$. Other carbohydrates were mannan, galactan, and arabinan with $0.34-0.85 \%, 0.39-1.26 \%$, and $0.46-1.94 \%$ depending on the pretreatment method. There was a remarkable increase in glucan fraction after the pretreatments. The glucan fraction increased by $41.9 \%$ and $26.4 \%$ after the pretreatment by sodium hydroxide and phosphoric acid, respectively. On the contrary, to glucan, other sugars decreased after the pretreatments. In addition, all pretreatments reduced the acid-soluble lignin and the minimum change, from $1.78 \%$ to $1.15 \%$, was observed in phosphoric acid pretreatment. The highest loss in acid soluble and insoluble lignin was observed in sodium hydroxide pretreatment where the total lignin content decreased from $18.2 \%$ to $12.5 \%$. However, an increase in acid-insoluble lignin content in phosphoric acid pretreated bagasse was detected.

The structural change in the bagasse was followed by FTIR analysis. As an example, the spectra of untreated and sodium hydroxide pretreated bagasse are presented in Fig. 1. Comparing the FTIR spectra of untreated and pretreated bagasse shows that the absorbance at $898 \mathrm{~cm}-1$, which is assigned to cellulose I, increased after pretreatment by sodium hydroxide. The total crystallinity indexes (TCI) that was defined as the absorbance ratio of $\mathrm{A}_{1430}$ to $\mathrm{A}_{898}$ were 0.83 and 0.73 for untreated and $\mathrm{NaOH}$ treated, respectively. In addition, the absorbance at about 3,350 $\mathrm{cm}-1$, which is related to $\mathrm{O}-\mathrm{H}$ stretching band of hydroxyl group, was increased after pretreatment by sodium hydroxide. Moreover, sodium hydroxide resulted in broadening at this wave number. This indicated the weaker intra- and intermolecular hydrogen bonding and lower crystallinity. Lignin characteristic can be followed by the peaks at $1218 \mathrm{~cm}-1$ (C-O of guaiacyl ring). The band intensity at this wavelength for pretreated materials was significantly lower than that of the untreated bagasse, indicating the delignification effect of the corresponding pretreatment.

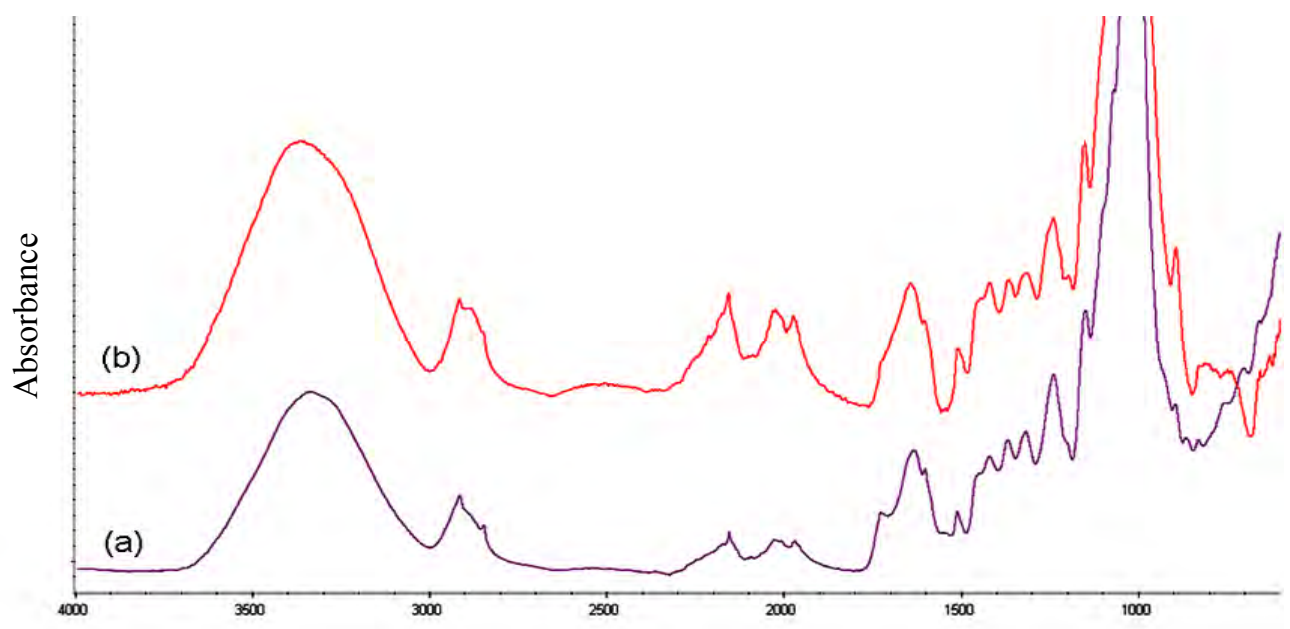

Fig. 1. FTIR spectra of (a) untreated bagasse and (b) NaOH pretreated bagasse.

SEM was used to study the morphological features and surface characteristics of materials after the pretreatment compared with the untreated bagasse. The pretreatment resulted in significant physical changes (Fig. 2). Both sodium hydroxide and concentrated phosphoric acid disrupt the structure of the fibers. Furthermore, the structure of the lignocellulosic biomass was opened up 
and more sponge-like structures were observed after the pretreatment that can provide higher surface area for subsequent enzymatic reactions.
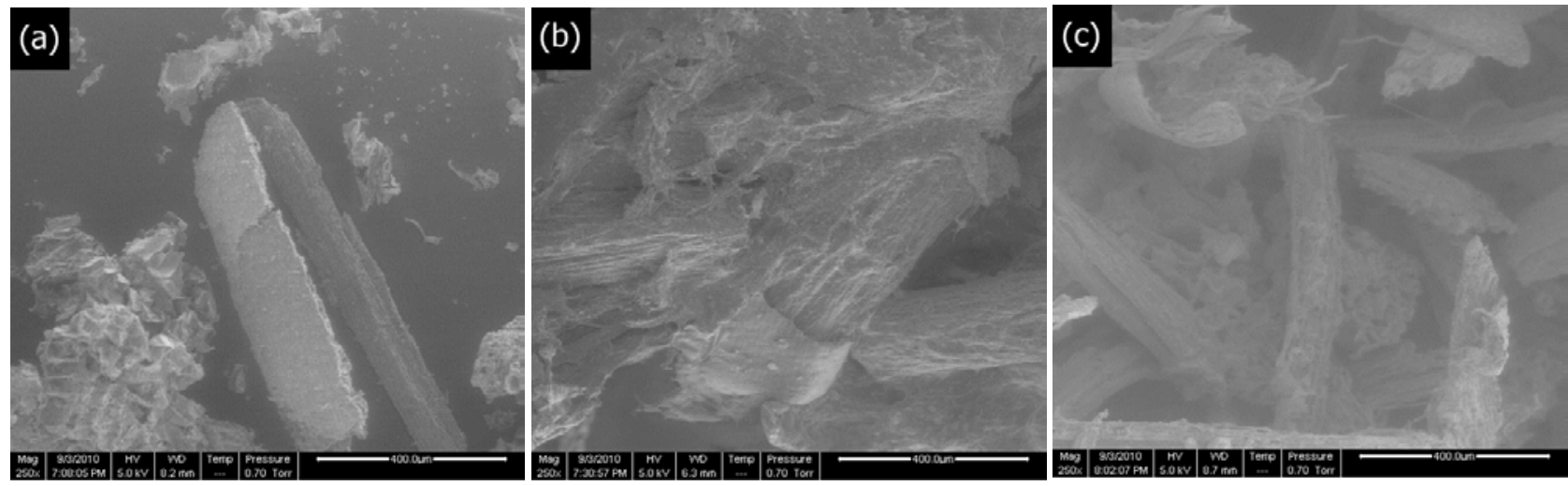

Fig. 2. SEM images of (a) untreated, (b) NaOH pretreated and (c) phosphoric acid pretreated bagasse.

\subsection{Enzymatic hydrolysis}

Different preparations of sweet sorghum bagasse were subjected to $72 \mathrm{~h}$ enzymatic hydrolysis by addition of cellulase and $\beta$-glucosidase. Pure cellulose was used as a reference in the hydrolysis experiments. The most important hydrolysis results are presented as percentages of theoretical sugar yield in Table 2. The yield of hydrolysis of native bagasse was effectively improved after sodium hydroxide and concentrated phosphoric acid pretreatments. The sugar content in the hydrolyzates increased sharply in the first $12 \mathrm{~h}$ and gradually continued until $72 \mathrm{~h}$. Hydrolysis of the untreated bagasse resulted in $42 \%$ and $65 \%$ conversion after $12 \mathrm{~h}$ and $72 \mathrm{~h}$, respectively. The hydrolysis yield increased from $65 \%$ to $79 \%$ after $30 \mathrm{~m}$ in pretreatment by concentrated phosphoric acid. The best results of enzymatic hydrolysis were obtained in the hydrolysis of pretreated bagasse by $\mathrm{NaOH}$ solution, where more than $92 \%$ of the theoretical glucose yield was obtained.

Table 2. Yield of enzymatic hydrolysis for the bagasse before and after the pretreatments.

\begin{tabular}{lccc}
\hline & \multicolumn{3}{c}{$\begin{array}{c}\text { Yield of enzymatic hydrolysis } \\
(\% \text { theoretical sugar yield })\end{array}$} \\
\cline { 2 - 4 } Pretreatment method $\backslash$ Hydrolysis time & $12 \mathrm{~h}$ & $24 \mathrm{~h}$ & $72 \mathrm{~h}$ \\
\hline Untreated & $42 \%$ & $43 \%$ & $65 \%$ \\
Avicell & $46 \%$ & $60 \%$ & $70 \%$ \\
$\mathrm{NaOH}$ & $79 \%$ & $80 \%$ & $92 \%$ \\
Phosphoric acid & $70 \%$ & $79 \%$ & $79 \%$ \\
\hline
\end{tabular}

\subsection{Discussion}

Sweet sorghum considered as a potential energy crop in nearly all temperate, subtropical, and tropical climates. It produces sugars juice, grains with high starch content, and bagasse. The bagasse is usually used for energy production by incineration. The native sweet sorghum bagasse which was used in the current work contains over $63 \%$ carbohydrate mainly in the form of glucan 
and xylan, respectively, and about $18 \%$ lignin, which is comparable with the typical composition of other agricultural residues. The present work dealt with the pretreatment of sweet sorghum bagasse by sodium hydroxide and phosphoric acid followed by enzymatic hydrolysis to fermentable sugars.

As expected, a pretreatment was necessary in order to efficiently convert the cellulose in the bagasse to fermentable sugars by hydrolytic enzymes. Besides, the pretreatment could increase the glucan fractions. The bagasse was partially delignified by sodium hydroxide pretreatment.

The FTIR technique can be applied to examine the structural changes in the biomass during pretreatments [13]. The analysis showed increasing the band intensity at $898 \mathrm{~cm}^{-1}$ and decreasing the band at $1,427 \mathrm{~cm}^{-1}$ which indicated the lower crystallinity and increasing the amorphous form of cellulose as a result of alkali pretreatment.

Also, the SEM images showed the rigid structure of untreated bagasse. The fibers of pretreated materials appear to be distorted and separated from the initial connected structure, thus increasing the external surface area and the porosity. Such improved morphological properties generated by pretreatments appeared to be the primary reason for the enhancement of enzymatic hydrolysis yield.

\subsection{Conclusion}

It can be concluded that the sweet sorghum bagasse is a r emarkable feedstock for ethanol production regarding to its easy cultivation and favor properties as well as high glucan fraction. The comparison between the hydrolysis results of pretreated and untreated bagasse proved that enzymatic hydrolysis of sweet sorghum bagasse could be significantly improved after pretreatment by sodium hydroxide and phosphoric acid. However, it seems that the sodium hydroxide is a more efficient pretreatment method before production of fermentable sugars from sweet sorghum bagasse for further processing to, e.g. ethanol.

\section{References}

[1] M. J. Taherzadeh and K. Karimi, Bioethanol: Market and Production Processes, in Biofuels refining and performance, A. Nag (Ed.), McGraw-Hill, 2008, pp. 69-106.

[2] Ó. J. Sánchez and C. A. Cardona, Trends in biotechnological production of fuel ethanol from different feedstocks, Bioresource Technology 99, 2008, pp. 5270-5295.

[3] M. J. Taherzadeh and K. Karimi, Pretreatment of lignocellulosic wastes to improve ethanol and biogas production: a review, International Journal of Molecular Sciences 9, 2008, pp. 1621-1651.

[4] X. R. Wu, et al., Features of sweet sorghum juice and their performance in ethanol fermentation, Industrial Crops and Products 31, 2010, pp. 164-170.

[5] S. Balint, et al., Sweet Sorghum as Feedstock for Ethanol Production: Enzymatic Hydrolysis of Steam-Pretreated Bagasse, Applied Biochemistry and Biotechnology 153, 2009, pp. 151162.

[6] M. J. Taherzadeh and K. Karimi, Enzyme-Based Hydrolysis Processes for Ethanol from Lignocellulosic Materials: A Review, Bioresources 2, 2007, pp. 707-738. 
[7] M. J. Taherzadeh and K. Karimi, Acid-Based Hydrolysis Processes for Ethanol from Lignocellulosic Materials: A Review, Bioresources 2, 2007, pp. 472-499.

[8] Y. H. P. Zhang, et al., Fractionating recalcitrant lignocellulose at modest reaction conditions, Biotechnology and Bioengineering 97, 2007, pp. 214-223.

[9] J. Xu, et al., Sodium Hydroxide Pretreatment of Switchgrass for Ethanol Production, Energy Fuels 24, 2010, pp. 2113-2119.

[10]B. Adeny and J. Baker, Measurement of Cellulase Activities, Laboratory Analytical Procedure (LAP), National Renewable Energy Laboratory, 2008.

[11]E. A. Ximenes, et al., Production of cellulases by Aspergillus fumigatus and characterization of one $\beta$-glucosidase, Current Microbiology 32, 1996, pp. 119-123.

[12]A. Sluiter, et al., Determination of Structural Carbohydrates and Lignin in Biomass, in Laboratory Analytical Procedure (LAP), National Renewable Energy Laboratory, 2008.

[13] S. Y. Oh, et al., FTIR analysis of cellulose treated with sodium hydroxide and carbon dioxide, Carbohydrate Research 340, 2005, pp. 417-428. 